\title{
Perancangan Dan Analisa Antena Yagi 12 Elemen Untuk Module Lora Rfm95w Pada Frekuensi $915 \mathrm{mhz}$
}

\author{
Fajar Alviandi $^{1}$, Koesmarijanto ${ }^{2}$, Hendro Darmono ${ }^{3}$ \\ ${ }^{1,3}$ Program Studi Jaringan Telekomunikasi Digital, \\ Jurusan Teknik Elektro, Politeknik Negeri Malang, Indonesia \\ ${ }^{2}$ Program Studi Teknik Telekomunikasi, \\ Jurusan Teknik Elektro, Politeknik Negeri Malang, Indonesia
}

${ }^{1}$ fajar.alviandi@gmail.com, ${ }^{2}$ koesmarijanto@polinema.ac.id, ${ }^{3}$ hendroodarmono@gmail.com

\begin{abstract}
The purpose of this research is to design a 12 element Yagi antenna so that it can be applied to the Lora RFM95W module which works at a frequency of $915 \mathrm{MHz}$, to find the effect of signal reception power on the Lora module. In this study, the implementation of the yagi antenna and built-in antenna was tested in line of sight and non-line of sight. The 12-element yagi antenna test results obtained a Return Loss of $-17.8 \mathrm{dBm}$ and a VSWR value of 1.29. The average gain obtained is $5.6 \mathrm{~dB}$. And the results of the implementation of the LOS state for a distance of 200 meters the yagi antenna has an RSSI value of $\mathbf{- 9 8} \mathrm{dBm}$, while the built-in lora antenna has a power level of $-109 \mathrm{dBm}$. The second test results in a Non-LOS (Wall Obstruction) state at a distance of $25 \mathrm{~m}$ the builtin antenna has an RSSI value of $-95 \mathrm{dBm}$, while the 12 element yagi antenna is $-77 \mathrm{dBm}$. The test results in Non-LOS (Tree Obstacle) at a distance of $25 \mathrm{~m}$ the built-in antenna has an RSSI value of $-84 \mathrm{dBm}$, while the 12 element yagi antenna is $-78 \mathrm{dBm}$. So that in the implementation of the 12 element yagi antenna and the built-in antenna, it can be concluded that for the RSSI data, the directional yagi antenna is better than the omnidirectional lora RFM95W antenna built-in antenna.
\end{abstract}

Keywords-Antenna, yagi antenna, LoRa, RSSI.

Abstrak - Pada penelitian bertujuan untuk merancang antena Yagi 12 elemen agar dapat diaplikasikan pada module Lora RFM95W yang bekerja pada frekuensi $915 \mathrm{MHz}$, untuk mencari pengaruh daya penerimaan sinyal terhadap module Lora. Dalam penelitian ini pengujian implementasi antena yagi dan antena built-in dilakukan dengan keadaan line of sight dan non-line of sight. Hasil pengujian antena yagi 12 elemen diperoleh Return Loss sebesar $-17.8 \mathrm{dBm}$ serta nilai VSWR yaitu 1.29. Rata-rata gain yang diperoleh sebesar 5.6 dB. Dan hasil implementasi keadaan LOS untuk jarak 200 meter antena yagi memiliki nilai RSSI sebesar $-98 \mathrm{dBm}$, sedangkan antena built-in lora memiliki level daya sebesar $-109 \mathrm{dBm}$. Hasil pengujian kedua dalam keadaan Non-LOS (Halangan Tembok) pada jarak $25 \mathrm{~m}$ antena built-in memiliki nilai RSSI sebesar $-95 \mathrm{dBm}$, sedangkan antena yagi 12 elemen sebesar $-77 \mathrm{dBm}$. Hasil pengujian dalam keadaan Non-LOS (Halangan Pohon) pada jarak $25 \mathrm{~m}$ antena built-in memiliki nilai RSSI sebesar -84 dBm, sedangkan antena yagi 12 elemen sebesar $\mathbf{- 7 8} \mathrm{dBm}$. Sehingga pada implementasi antena yagi 12 elemen dan antena built-in dapat disimpulkan untuk data RSSI lebih baik antena yagi yang bersifat directional daripada antena built-in antena lora RFM95W yang bersifat omnidirectional.

Kata kunci-Antena, Antena yagi, LoRa, RSSI.

\section{PENDAHULUAN}

Seiring perkembangan zaman masa kini yang dituntut untuk meningkatkan segala jenis teknologi agar menjadi teknologi mutakhir yang lebih efektif dan memiliki kualitas yang lebih baik dari sebelum - sebelumnya, salah satunya adalah teknologi di bidang telekomunikasi. Teknologi telekomunikasi yang sebelumnya menggunakan media kabel (wireline) sekarang sudah berganti dengan teknologi tanpa media kabel (wireless) yang menggunakan gelombang radio sebagai media transmisi datanya. Salah satu teknologi yang mendukung gelombang radio transmisi

data tersebut adalah Wireless Sensor Network (WSN). WSN adalah sebuah network ad-hoc yang berbentuk perangkat kecil dengan kapasitas energi yang terbatas[1]. Salah satu perangkat WSN yang dapat melakukan transmisi data berbasis wireless adalah module lora RFM95W yang bekerja pada frekuensi $915 \mathrm{Mhz}$.

Module Lora RFM95W merupakan perangkat yang dapat digunakan untuk mendukung sistem transmisi data dengan jarak jangkauan yang luas dan bisa mengirimkan data yang cukup besar. Module lora RFM95W ini tergolong perangkat yang berukuran kecil dan didukung oleh antena sebagai alat pendukung module lora RFM95W ini agar dapat mencakup jangkauan yang luas. Antena adalah sebuah perangkat yang berguna untuk mengirim dan menerima sebuah sinyal. Antena memiliki banyak macam bentuknya sesuai dengan fungsi dari penerapannya. Antena yang umum digunakan untuk Module lora RFM95W adalah antena jenis omnidirectional yakni merupakan jenis antena yang memiliki pola pancaran sinyal ke segala arah dan jarak yang relatif pendek. Hal itu dapat memungkinkan daya yang di terima oleh receiver menjadi kecil di karenakan pancaran sinyal yang terbagi ke segala arah membuat perangkat module lora RFM 95W memiliki daya yang kurang baik [2].

Oleh karena itu peneliti membuat rancangan antena yang dapat mendukung perangkat module lora RFM95W agar memiliki daya yang lebih baik dari antena yang telah digunakan pada umumnya dan tentunya hal ini dapat mengefektifkan kualitas module lora RFM95W [3]. Jenis antena yang akan dibuat oleh penelitian adalah sebuah antena yagi atau yang dikenal dengan yagi uda. Secara luas antena yagi ini merupakan antena yang banyak digunakan sebagai aplikasi RF direktif. Antena yagi sendiri adalah antena directional yang bersifat menerima sinyal hanya pada satu arah yaitu arah depan, dikarenakan sisi antena yagi yang ada pada belakang reflector memiliki gain yang lebih kecil daripada di depan director[3]. Sehingga dapat dikatakan 
antena yagi ini memiliki keunggulan dalam hal keterarahan yang membuat gain antena yagi akan lebih besar pada arah tertentu.

\section{METODE}

\section{A. Perancangan Penelitian}

Tahapan penelitian yang akan dilakukan dinyatakan dengan diagram alur yang tertera pada Gambar 1.

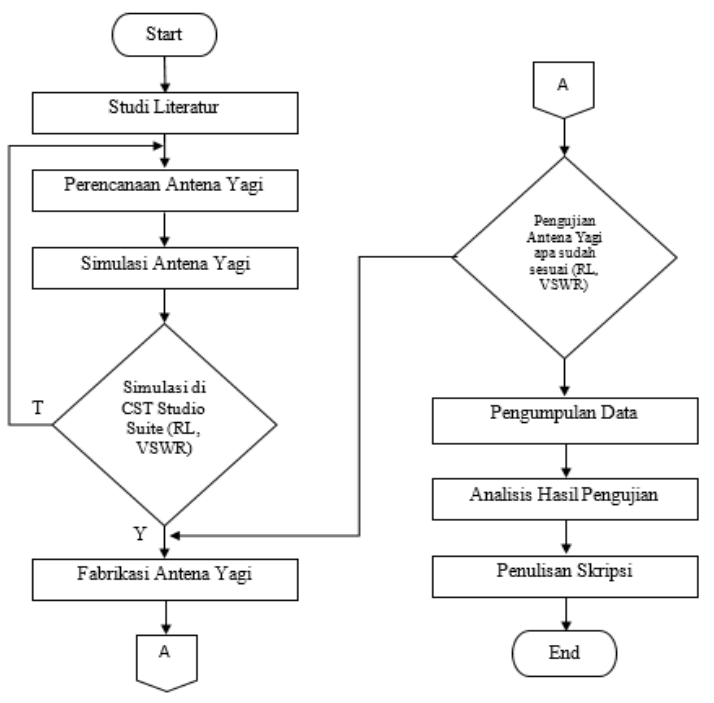

Gambar 1. Diagram Alur Penelitian

\section{B. Perancangan Prosedur Implementasi}

Tahapan prosedur Implementasi yang akan dilakukan dengan diagram yang tertera pada Gambar 2 .

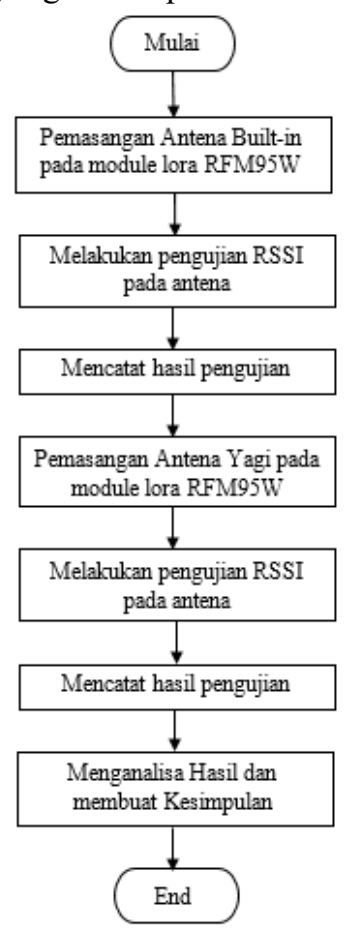

Gambar 2. Diagram Prosedur Implementasi

\section{Perencanaan Antena}

Melakukan perencanaan berupa menghitung menggunakan rumus-rumus dasar antena untuk mendapatkan hasil berupa parameter-parameter pada antenna yagi 12 elemen dan bentuk antena yang diharapkan. Antena yagi mempunyai beberapa parameter fisik antara lain, jarak antar elemen (S), panjang elemen (L), dan kecepatan cahaya(C). Frekuensi kerja antena adalah 915 $\mathrm{MHz}$.

- Penentuan Panjang Gelombang

$$
\begin{aligned}
\lambda & =\frac{c}{f} \\
& =\frac{3 \times 10^{8}}{915 \times 10^{6}}=0.328 \mathrm{~m}=328 \mathrm{~mm}
\end{aligned}
$$

- $\quad$ Penentuan Dimensi Driven elemen (Folded Dipole) (jarak antara elemen folded $0,05 \lambda$ ).

$$
\begin{aligned}
L & =0.45 \times \lambda \\
& =0.45 \times 0.328 \\
& =0.1476 \mathrm{~m}=147.6 \mathrm{~mm} \\
S & =0.05 \times \lambda \\
& =0.05 \times 0.328 \\
& =0.0164 \mathrm{~m}=16.4 \mathrm{~mm}
\end{aligned}
$$

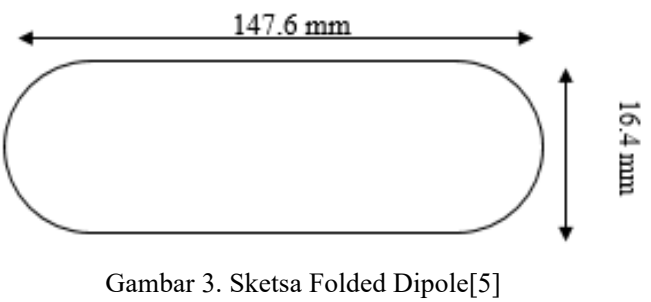

- Penentuan Dimensi Reflector

$$
\begin{aligned}
L_{\text {refl }} & =(0.5 \times \lambda)+5 \% \\
& =(0.5 \times 328)+5 \% \\
& =164+7.38 \\
& =171.38 \mathrm{~mm}
\end{aligned}
$$

- Penentuan Dimensi Balun Antena

$$
\begin{aligned}
L_{\text {Balun }} & =0.5 \times \lambda \times V f \\
& =129.56 \mathrm{~mm}
\end{aligned}
$$

- Penentuan dimensi director antena $L_{d 1}=0.440 \times \lambda=144.32 \mathrm{~mm}$ $L_{d 2}=0.435 \times \lambda=142.68 \mathrm{~mm}$ $L_{d 3}=0.430 \times \lambda=141.04 \mathrm{~mm}$ $L_{d 4}=0.425 \times \lambda=139.4 \mathrm{~mm}$ $L_{d 5}=0.435 \times \lambda=142.68 \mathrm{~mm}$ $L_{d 6}=0.430 \times \lambda=141.04 \mathrm{~mm}$ $L_{d 7}=0.440 \times \lambda=144.32 \mathrm{~mm}$ $L_{d 8}=0.435 \times \lambda=142.68 \mathrm{~mm}$ $L_{d 9}=0.430 \times \lambda=141.04 \mathrm{~mm}$ $L_{d 10}=0.430 \times \lambda=141.04 \mathrm{~mm}$

- Penentuan jarak antar elemen

$S_{\text {refl-driven }}=0.35 \times \lambda$ 
Jurnal Jaringan Telekomunikasi, E-ISSN: 2654-6531, P-ISSN: 2407-0807, Vol. 11, No. 1 (2021) 44-49

$$
\begin{aligned}
& =114.8 \mathrm{~mm} \\
S_{\text {driven-d1 }} & =0.25 \times \lambda \\
& =82 \mathrm{~mm} \\
S_{d 1-d 2} & =0.15 \times \lambda \\
& =49.2 \mathrm{~mm} \\
S_{d 2-d 10} & =0.2 \times \lambda \\
& =65.6 \mathrm{~mm}
\end{aligned}
$$

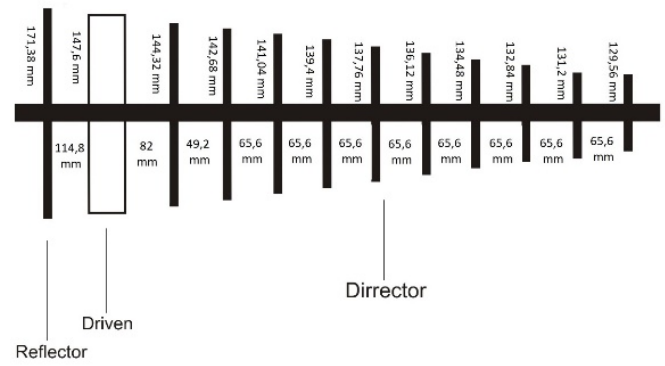

Gambar 4. Desain Antena Yagi 12 Elemen[6]

\section{Desain Antena dan simulasi}

Simulasi perancangan antena Yagi yang bekerja pada frekuensi $915 \mathrm{MHz}$ ini dibuat dengan menggunakan software CST. Simulasi ini dilakukan untuk mengetahui kinerja dari antenna yang telah dirancang melalui perhitungan.

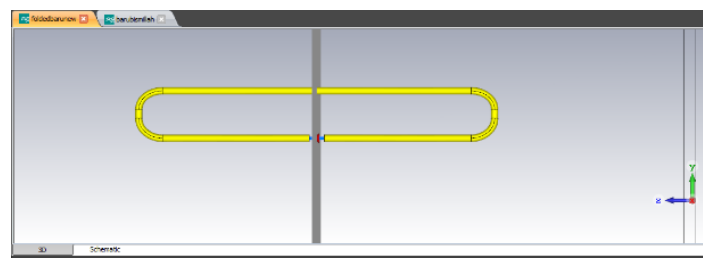

Gambar 5. Desain folded dipole

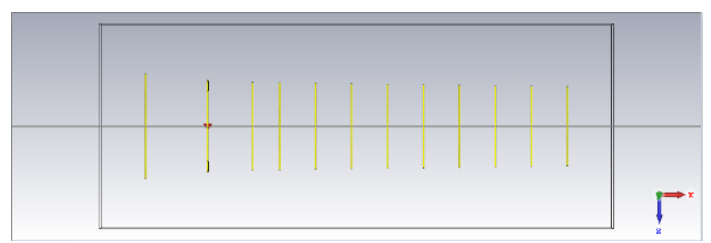

Gambar 6. Desain antena yagi 12 elemen

\section{E. Fabrikasi Antena}

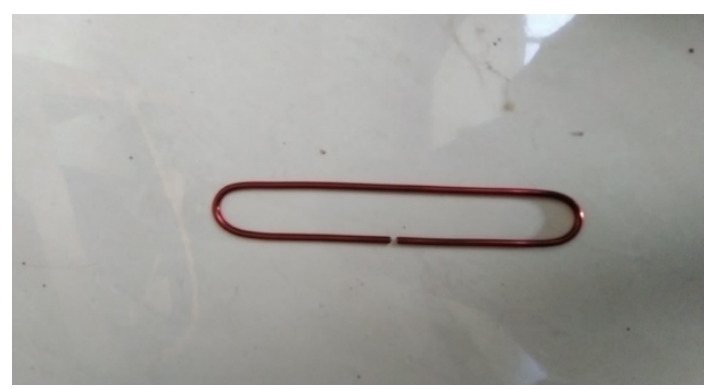

Gambar 7. Hasil fabrikasi folded dipole

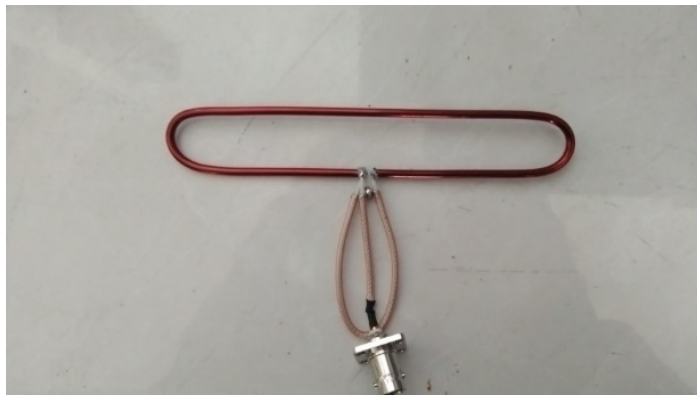

Gambar 8. Pemasangan Balun pada folded dipole

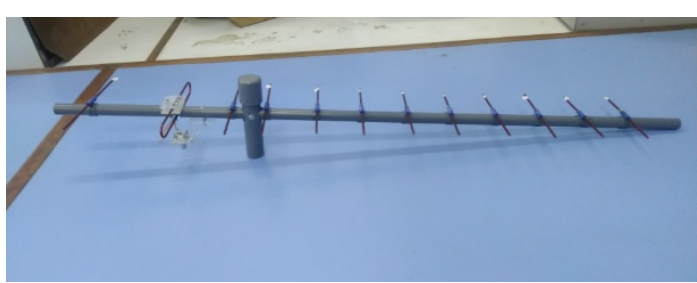

Gambar 9. Hasil Fabrikasi antena yagi 12 elemen

\section{HASIL DAN PEMBAHASAN}

\section{A. Hasil Simulasi}

\section{1) Simulasi antena yagi 12 elemen di CST}

Hasil simulasi Return Loss yang dilakukan bernilai $26.076 \mathrm{~dB}$. Nilai tersebut telah kurang $-10 \mathrm{~dB}$ yang menjadi syarat antenna yang baik.

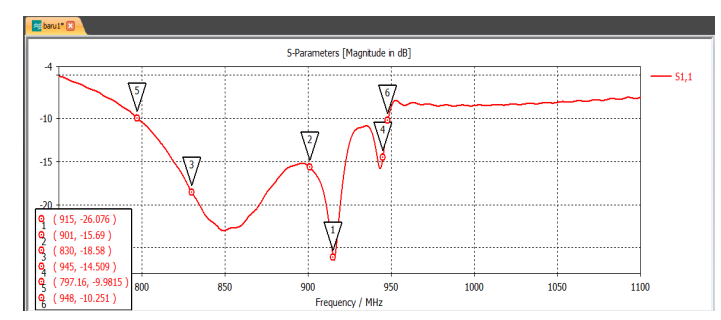

Gambar 10. Hasil simulasi Return Loss antenna Yagi 12 elemen

Hasil simulasi VSWR dari desain antenna yang telah dirancang sebesar 1.1046. nilai tersebut dianggap telah memenuhi spesifikasi antenna, yaitu $\leq 2$.

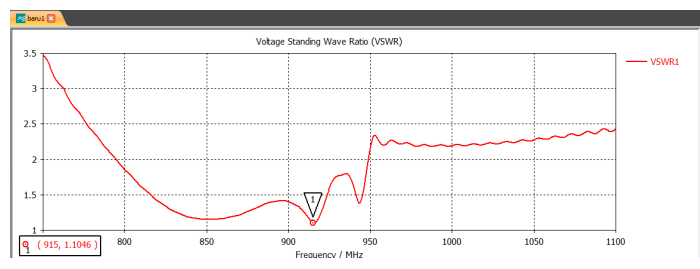

Gambar 11. Hasil simulasi VSWR Antena Yagi 12 Elemen

\section{B. Hasil Pengujian Antena}

1) Hasil Pengujian Return Loss

- Hasil pengujian Return Loss dan VSWR antena Yagi 12 Elemen 
Hasil pengujian Return Loss dan VSWR antena Yagi 12 elemen.Nilai level daya dari antena yang diuji dapat dilihat pada gambar 12 .

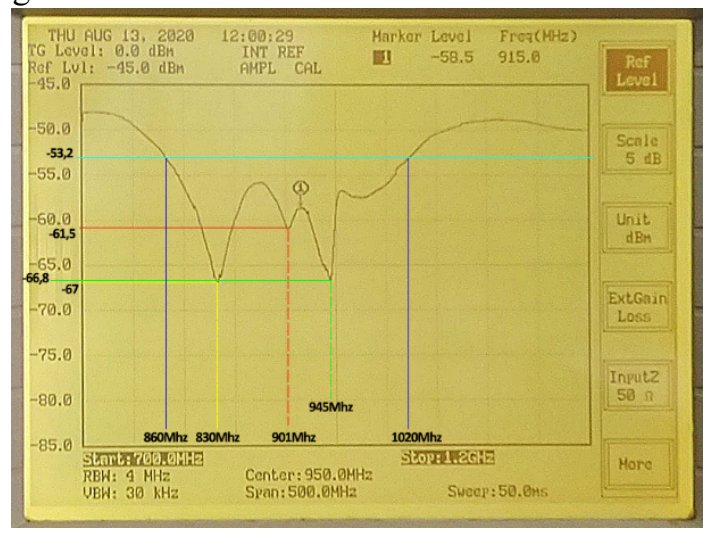

Gambar 12. Hasil pengujian Return Loss antena Yagi 12 elemen

Nilai level daya yang telah diperoleh digunakan untuk menghitung nilai Return Loss. Dengan persamaan berikut: $\mathrm{R}_{\mathrm{L}}=$ Level $_{\mathrm{AUT}}-$ Level $_{\text {reff }}-$ Level $_{\mathrm{DC}}$

Keterangan:

$\mathrm{R}_{\mathrm{L}}:$ Return Loss

Level $_{\mathrm{AUT}}$ : level daya dari antena yang diuji

Level $_{\text {reff }}$ : level daya referensi

Level $_{\mathrm{DC}}$ : attenuasi dari directional copler

Nilai Return Loss akan digunakan untuk mencari nilai koefisien pantul yang nantinya nilai koefisien pantul digunakan untuk menghitung nilai VSWR.

$$
\mathrm{R}_{\mathrm{L}}=20 \log |\Gamma|
$$

Keterangan:

$\Gamma=$ Koefisien pantul

Mnghitung nilai VSWRnya dengan persamaan :

$$
V S W R=\frac{1+|\Gamma|}{1-|\Gamma|}
$$

Nilai VSWR yang diperoleh sebagai berikut :

TABEL 1.

\begin{tabular}{|c|c|c|c|c|c|}
\hline \multirow{2}{*}{$\begin{array}{c}\text { Frekuens } \\
\text { i (MHz) }\end{array}$} & \multicolumn{4}{|c|}{ Level dBm } & \multirow[b]{2}{*}{ VSWR } \\
\hline & Terbaca & Ref & $\begin{array}{r}\text { ATT } \\
\text { DC }\end{array}$ & RL & \\
\hline 915 & -58.5 & -23.2 & -20 & -15.3 & 1,41 \\
\hline 901 & -61.5 & -23.7 & -20 & $-17,8$ & 1,29 \\
\hline 945 & -66.8 & -23.2 & -20 & -23.6 & 1,141 \\
\hline 830 & -67 & -23.5 & -20 & -23.5 & 1,141 \\
\hline
\end{tabular}

HASIL PENGUJIAN RETURN LOSS DAN VSWR

\section{2) Hasil Pengujian Gain}

- Hasil Pengujian Gain Antena Yagi 12 Elemen
Hasil pengujian gain yang didapatkan direpresentasikan pada tabel dan grafik berikut ini.

TABEL 2.

HASIL PENGUJIAN GAIN

\begin{tabular}{cccc}
\hline $\begin{array}{c}\text { Frekuensi } \\
(\mathbf{M H z})\end{array}$ & Levelref & LevelAUT & Gain (dBi) \\
\hline 885 & $-44,4$ & $-38,1$ & 8,45 \\
\hline 895 & $-50,4$ & $-41,4$ & 11,15 \\
\hline 905 & -51 & $-41,2$ & 11,95 \\
\hline 915 & $-49,1$ & $-46,1$ & 5,15 \\
\hline 925 & $-62,8$ & $-43,8$ & 21,15 \\
\hline 935 & $-63,6$ & $-49,8$ & 15,95 \\
\hline 945 & $-50,6$ & $-41,7$ & 11,05 \\
\hline 955 & $-51,2$ & $-52,7$ & 0,65 \\
\hline & Rata - Rata & & 4,071428571 \\
\hline & & &
\end{tabular}

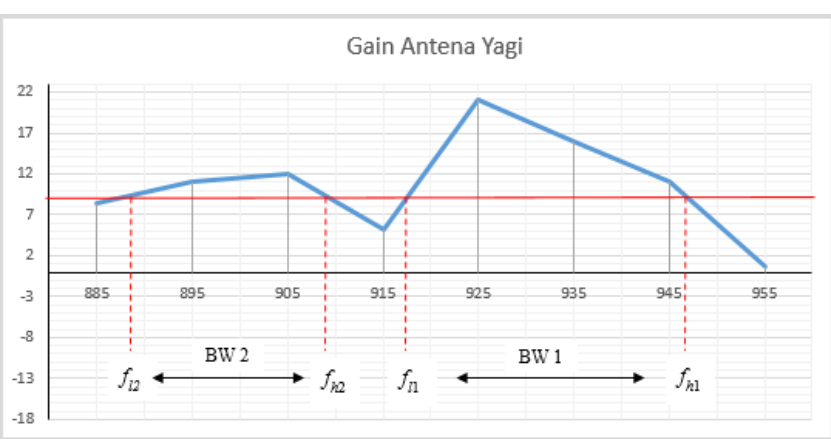

Gambar 13. Grafik pengujian gain Antena Yagi 12 elemen

Gain terbesar diperoleh sebesar 21,15 dB di frekuensi 925 $\mathrm{MHz}$, sedangkan gain terkecil diperoleh pada frekuensi 955 $\mathrm{MHz}$ yaitu 0,65 dB. Dari tabel pengujian gain dapat dibuat grafik untuk mengetahui nilai bandwidthnya dengan menentukan nilai maksimal gain yang didapatkan. Nilai gain yang didapat selanjutnya akan dikurangkan $-3 \mathrm{~dB}$. Bandwidth 1 yang didapatkan sebagai berikut.

Bw1 = f_h1-f_11

Bw1 $=947-918$

$\mathrm{Bw} 1=27 \mathrm{MHz}$

Bandwidth 2 yang didapatkan sebagai berikut

$\mathrm{Bw} 2=\mathrm{f}$-h2-f_12

$\mathrm{Bw} 2=909-888$

$\mathrm{Bw} 2=21 \mathrm{MHz}$

Sehingga total bandwidth adalah:

Bwtotal $=$ Bw1 + Bw2

$$
\begin{aligned}
& =27+21 \mathrm{MHz} \\
& =48 \mathrm{MHz}
\end{aligned}
$$

3) Hasil Pengujian Pola Radiasi Antena Yagi 12 elemen

Nilai HPBW direpresentasikan dengan melakukan pengurangan nilai sudut tertinggi dengan sudut terendah 
yang menghubungkan titik pusat lingkaran dengan titik daya bernilai sebesar $-3 \mathrm{~dB}$.

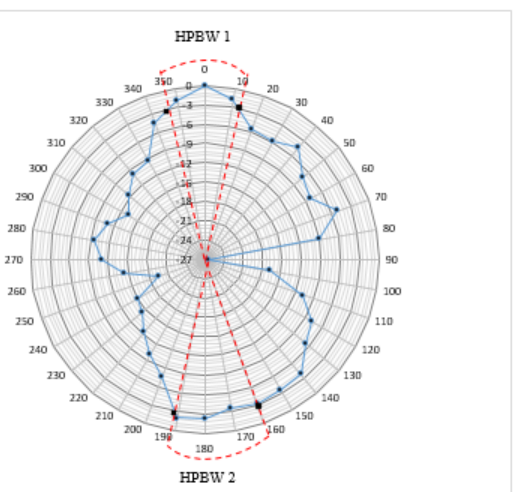

Gambar 14. Diagram polar pola radiasi untuk antena yagi 12 elemen

Bentuk yang dihasilkan oleh pola radiasi yaitu bersifat omnidirectional. Nilai HPBW berdasarkan diagram polar dapat diketahui yaitu sebagai berikut:

- HPBW 1

$\mathrm{HPBW} 1=\left(360^{\circ}-347^{\circ}\right)+12^{\circ}$

$\mathrm{HPBW} 1=13^{\circ}+12^{\circ}=25^{\circ}$

- HPBW 2

$\mathrm{HPBW} 2=191^{\circ}-160^{\circ}$

$\mathrm{HPBW} 2=31^{\circ}$

- HPBW total

HPBW total $=25^{\circ}+31^{\circ}$

HPBW total $=56^{\circ}$

Jadi nilai HPBW total yang didapatkan sebesar $56^{\circ}$

Pola radiasi yang ditampilkan pada diagram polar antena yagi 12 elemen yaitu bidirectional.

\section{Hasil Implementasi Antena}

Pengujian dilakukan dalam keadaan line of sight dan nonline of sight, yang pertama dalam keadaan line of sight dengan jarak 10 meter - 200 meter, Pengujian selanjutnya dalam keadaan non-line of sight (Tembok dan Pohon) dengan jarak 5 meter - 25 meter. Data yang diambil adalah level daya yang diterima oleh kedua antena yang diuji.
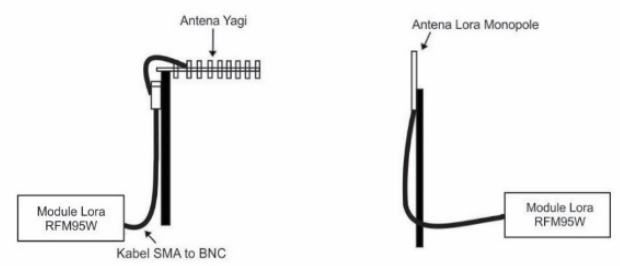

Gambar 15. Blok Diagram Antena Yagi sebagai penerima
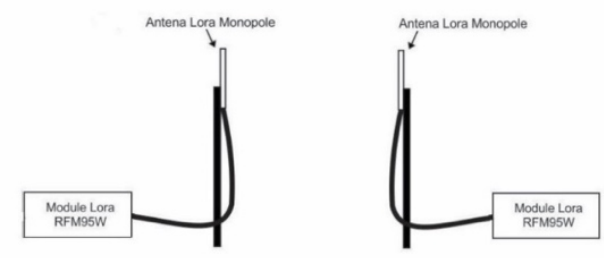

Gambar 16. Blok Diagram Antena Built-in sebagai penerima

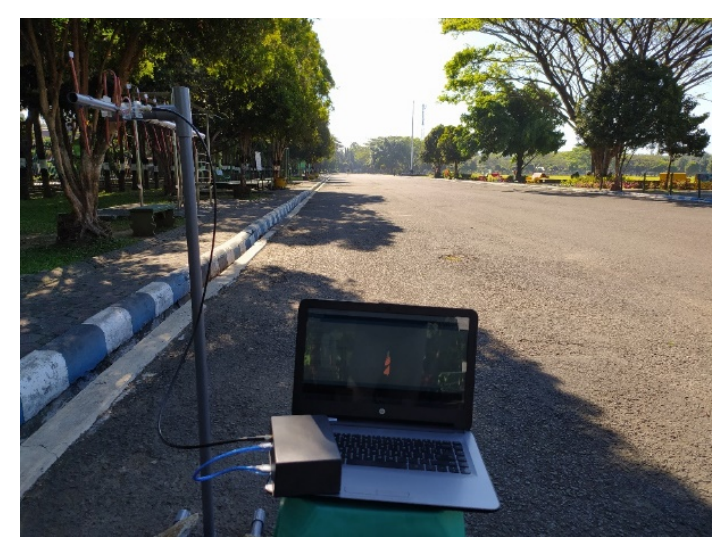

Gambar 17. Pengujian Antena Yagi 12 Elemen keadaan Los

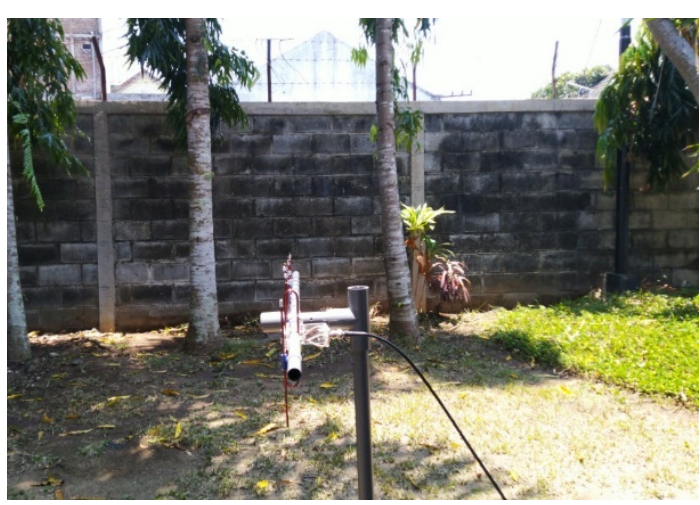

Gambar 18. Pengujian Antena Yagi 12 Elemen keadaan Non-Los (Tembok)

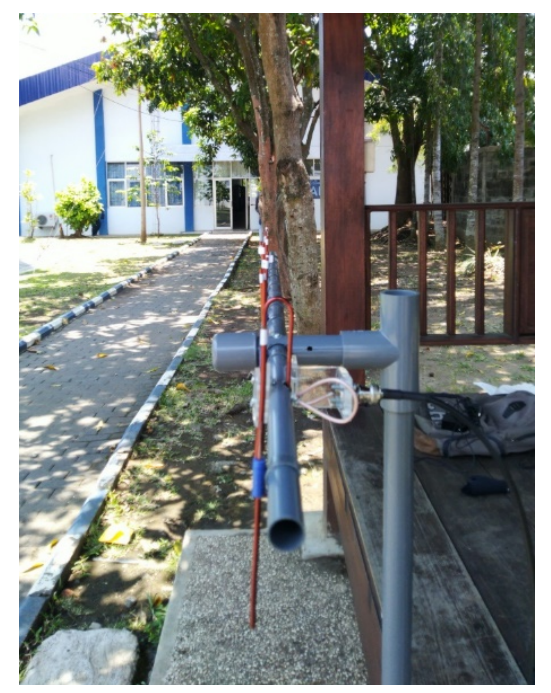

Gambar 19. Pengujian Antena Yagi 12 Elemen keadaan Non-Los (Pohon)

TABEL 3.

HASIL PENGAMBILAN DATA RSSI NON-LOS

\begin{tabular}{ccc} 
HASIL PENGAMBILAN DATA RSSI NON-LOS \\
\hline JARAK & $\begin{array}{c}\text { RSSI ANTENA } \\
\text { BUILT-IN }\end{array}$ & $\begin{array}{c}\text { RSSI ANTENA } \\
\text { YAGI }\end{array}$ \\
\hline 10 & -65 & -64 \\
\hline 20 & -70 & -66 \\
\hline 30 & -74 & -70 \\
\hline 40 & -78 & -73 \\
\hline 50 & -81 & -74 \\
\hline 60 & -83 & -76 \\
\hline
\end{tabular}




\begin{tabular}{|c|c|c|c|c|}
\hline JARAK & \multicolumn{2}{|c|}{$\begin{array}{l}\text { RSSI ANTENA } \\
\text { BUILT-IN }\end{array}$} & \multicolumn{2}{|c|}{$\begin{array}{c}\text { RSSI ANTENA } \\
\text { YAGI }\end{array}$} \\
\hline \multicolumn{2}{|c|}{70} & -86 & \multicolumn{2}{|c|}{-78} \\
\hline 80 & \multicolumn{2}{|r|}{-87} & \multicolumn{2}{|c|}{-80} \\
\hline 90 & \multicolumn{2}{|r|}{-89} & \multicolumn{2}{|c|}{-81} \\
\hline 100 & \multicolumn{2}{|r|}{-94} & \multicolumn{2}{|c|}{-83} \\
\hline 150 & \multicolumn{2}{|r|}{-99} & \multicolumn{2}{|c|}{-93} \\
\hline 200 & \multicolumn{2}{|r|}{-109} & \multicolumn{2}{|c|}{-98} \\
\hline \multicolumn{5}{|c|}{$\begin{array}{l}\text { TABEL } 4 . \\
\text { HASIL PENGAMBILAN DATA RSSI LOS(POHON DAN TEMBOK }\end{array}$} \\
\hline \multirow[t]{2}{*}{$\begin{array}{l}\text { JARA } \\
\mathbf{K}\end{array}$} & \multicolumn{2}{|c|}{$\begin{array}{l}\text { RSSI ANTENA } \\
\text { BUILT-IN }\end{array}$} & \multicolumn{2}{|c|}{$\begin{array}{l}\text { RSSI ANTENA } \\
\text { YAGI }\end{array}$} \\
\hline & $\begin{array}{c}\text { TEMBO } \\
\text { K }\end{array}$ & POHON & $\begin{array}{c}\text { TEMBO } \\
\text { K }\end{array}$ & POHON \\
\hline 5 & -74 & -69 & -59 & -63 \\
\hline 10 & -78 & -73 & -65 & -69 \\
\hline 15 & -84 & -75 & -68 & -73 \\
\hline 20 & -90 & -80 & -73 & -75 \\
\hline 25 & -95 & -84 & -77 & -78 \\
\hline
\end{tabular}

\section{KESIMPULAN}

Hasil Simulasi antena yagi 12 elemen didapatkan hasil frekuensi resonan yaitu $915 \mathrm{Mhz}$ dengan hasil return loss sebesar -26.076 dBm serta nilai VSWR yaitu 1.103. Sedangkan pada hasil fabrikasi frekuensi resonan yaitu 901 MHz dengan hasil return loss sebesar $-17.8 \mathrm{dBm}$ serta nilai VSWR yaitu 1.29. Pada pengukuran Polaradiasi, antena yagi 12 elemen memiliki polaradiasi bidirectional dengan HPBW sebesar $56^{\circ}$ pada posisi horizontal. Hasil pengujian gain antena yagi 12 elemen diperoleh gain rata-rata sebesar 4,0 dB. Hasil implementasi antena yagi 12 elemen dan antena built-in dapat disimpulkan untuk level daya diterima lebih baik antena yagi yang bersifat directional daripada antena built-in antena lora RFM95W yang bersifat omnidirectional. Untuk pengujian dalam keadaan Line Of Sight pada jarak $200 \mathrm{~m}$ antena yagi memiliki nilai level daya sebesar $-98 \mathrm{dBm}$, sedangkan antena built-in memiliki level daya sebesar -109 $\mathrm{dBm}$. Untuk pengujian dalam keadaan Non-Line Of Sight(Halangan Tembok) pada jarak $25 \mathrm{~m}$ antena yagi memiliki nilai level daya sebesar $-77 \mathrm{dBm}$. Sedangkan antena built-in memiliki level daya sebesar $-95 \mathrm{dBm}$. Untuk pengujian dalam keadaan Non-Line Of Sight(Halangan Pohon) pada jarak $25 \mathrm{~m}$ antena yagi memiliki nilai level data sebesar $-78 \mathrm{dBm}$. Sedangkan antena built-in memiliki nilai level daya sebesar $-84 \mathrm{dBm}$.

\section{REFERENSI}

[1] Susanto, Alfian Rizky, Adhitya Bhawiyuga, Kasyful Amron (2019). Implementasi Sistem Gateway Discovery pada Wireless Sensor Network (WSN) Berbasis Modul Komunikasi LoRa. Jurnal Pengembangan Teknologi Informasi dan Ilmu Komputer, Vol. 3, No 2, 2138 -2145.

[2] R. H. Y. Perdana, H. Hudiono and A. F. N. Luqmani, "Water Leak Detection and Shut-Off System on Water Distribution Pipe Network Using Wireless Sensor Network," 2019 International Conference on Advanced Mechatronics, Intelligent Manufacture and
Industrial Automation (ICAMIMIA), 2019, pp. 297301.

[3] H. Hudiono, M. Taufik, R. H. Y. Perdana, and W. R. Rohmah, "Design and implementation of centralized reading system on analog postpaid water meter," in IOP Conference Series: Materials Science and Engineering, 2020, vol. 732, no. 1.

[4] Sari, Christianna Wulan, Titani Silviana Hidayat (2017). Laporan Antena Yagi-Uda 11 Elemen dengan Frekuensi 900 MHz, Depok: Politeknik Negeri Jakarta Program Studi Teknik Telekomunikasi.

[5] fandy himawan, "Yagi Antenna Design and Analysis 11 Folded Dipole Feeding Elements for VoIP Networks", Jartel, vol. 1, no. 1, pp. 19-25, Mar. 2015.

[6] Sujendro, Herry. (2013). Perekayasaan Sistem Antena. Jakarta: Kementerian Pendidikan dan Kebudayaan. 